\title{
The Impact of Ride-Hailing Services on Private Car Use in Urban Areas: An Examination in Chinese Cities
}

\author{
Jun Zhong, Yan Lin (iD, and Siqi Yang \\ Department of Management Science and Engineering, Dalian Maritime University, 116026 Dalian, China \\ Correspondence should be addressed to Yan Lin; linyan@dlmu.edu.cn
}

Received 6 May 2020; Revised 23 October 2020; Accepted 29 October 2020; Published 23 November 2020

Academic Editor: Michela Le Pira

Copyright (c) 2020 Jun Zhong et al. This is an open access article distributed under the Creative Commons Attribution License, which permits unrestricted use, distribution, and reproduction in any medium, provided the original work is properly cited.

\begin{abstract}
The rapid development of internet-based ride-hailing services has contributed to transportation in cities and, at the same time, has significantly impacted existing travel modes in cities. A question has emerged as to whether and to what extent ride-hailing services replace private car use. Although the private car is convenient, comfortable, and flexible, it has low utilization rate and high maintenance and parking costs. Better understanding of the relationship between ride-hailing services and the use of private cars has been brought to the forefront for auto dealers and urban transportation policymakers. However, controversies remain regarding how ride-hailing services will impact the use of private cars in cities. Given this setting, our study applied a difference-indifferences method to analyze the impact of ride-hailing services on the use of private cars with balanced panel data from 109 prefecture-level cities in China from 2010 to 2016. Moreover, we employed some methods to verify the robustness of the preliminary results. The empirical results show that ride-hailing services had a negative impact on the use of private cars in urban areas. Over time, the negative impact initially strengthened and then weakened. Further studies showed that ride-hailing services had a more significant negative impact on private car use in eastern cities than in western cities. The results showed that the influence of ride-hailing services on private car use in urban areas is heterogeneous across time and cities.
\end{abstract}

\section{Introduction}

As the use of Internet is becoming more widespread and smartphone usage is increasing, a sharing economy platform came into being in recent years that helps ride-hailing services, such as Uber and Didi Chuxing, which thrive in the context of the sharing economy. A ride-hailing services in China has been defined as follows: "the service platform built based on Internet technology, enabling eligible cars and drivers to access the service platform and integrating supply and demand information so as to provide passengers with noncruise taxi reservation service" (see the website of the Ministry of Transport of the People's Republic of China for more details at http://xxgk.mot.gov.cn/jigou/fgs/201607/

t20160728_2973471.html). The ride-hailing services provide a real-time, efficient, and convenient supply-demand matching mechanism for passengers and drivers through the platform [1].
According to the 44th Statistical Report on Internet Development in China released by the China Internet Network Information Center (CNNIC), in June 2019 (available in Chinese at http://www.cac.gov.cn/2019-08/30/ c_1124938750.html), the number of online taxi bookings in China reached 337 million, an increase of 6.7 million compared with the end of 2018 and accounting for $39.4 \%$ of total Internet users. The rapid growth of ride-hailing services is bound to have a greater impact on urban transportation. Moreover, it will have an impact on urban traffic congestion and environmental pollution. The impact of ride-hailing services on urban traffic is a problem that urban transportation administrators and government policymakers consider closely.

In the past few years, with the development of the Chinese economy and the improvement in people's living standards, more and more people purchase private cars. Even though the private car is convenient, comfortable, and flexible, it has a low utilization rate and can cause a series of 
problems, including urban traffic congestion and environmental pollution [2].

In comparison, ride-hailing services can reduce travel costs, improve vehicle utilization, and reduce traffic congestion, environmental pollution, and parking pressure $[3,4]$. Therefore, the relationship between ride-hailing services and the use of private cars in urban settings is an issue worth studying. It will enrich studies on the impact of emerging ride-hailing services on traditional travel patterns [5-7].

If ride-hailing services can significantly reduce the use of private cars, it may alleviate urban traffic problems and environmental pollution. This research has implications and significance for the governance of ride-hailing services. In addition, whether and to what extent ride-hailing services decrease the use of private cars is an issue of concern for ride-hailing platform companies and car sales companies.

Ride-hailing services, as an emerging travel mode, have been underdeveloped and continue to change. At present, although many scholars have focused on ride-hailing services, research on the impact of ride-hailing services on traditional modes of travel, which mainly include traditional taxis, public transit, and private car use, is still very limited [8-10]. In the relevant literature, research on the influence on private car use is still very immature.

Existing research studies provide highly controversial conclusions and seldom fully clarify the relationship between the two sides $[2,11]$. For example, Ward et al. found that Uber and Lyft have reduced the average use of private cars by $4.1 \%$ in urban areas of the United States [12], but Gong et al. reported a contrary finding that Uber has increased new vehicle registrations by $8 \%$ in China [13].

This paper is devoted to addressing the limitations of previous studies. The impact of ride-hailing services on the use of private cars in different urban areas is analyzed, and the paper utilizes a more highly scientific, reasonable, and rigorous research design than that used in previous studies. In addition, rational choice theory and prospect theory are used to analyze the reasons that citizens choose one mode of transportation over another.

Uber and Didi Chuxing account for a large proportion of ride-hailing services in China. In 2014, they both started ridehailing services in China. They entered seven large cities in that year: Beijing, Shanghai, Guangzhou, Shenzhen, Chongqing, Chengdu, and Hangzhou. Over the next few years, they continuously entered other cities. The major ride-hailing services entered different cities at different times. This timeline provides favorable conditions for natural experiments to analyze the changes in the use of private cars in urban areas before and after large-scale ride-hailing services enter cities.

This paper collected balanced panel data from 109 cities in China from 2010 to 2016 to study the impact of ridehailing services on private car use in urban areas. In particular, this paper addresses the following questions. (1) How do ride-hailing services affect private car use in urban areas? (2) Is the impact of ride-hailing services on private car use in urban areas long term? (3) Is there urban location heterogeneity in the influence of ride-hailing services on private car use in urban areas?
The answers to these questions can provide the basis for the formulation of ride-hailing policies for urban transport administrators and are significant for automobile dealers with regard to the formulation of marketing strategies.

The elements of this study are arranged as follows. Section 2 outlines the findings of literature review, and Section 3 describes the empirical test design. Section 4 provides a description of the empirical analysis. The robustness test is discussed in Section 5, and Section 6 outlines the findings regarding the heterogeneity of urban locations. Section 7 provides a discussion and conclusion.

\section{Literature Review}

2.1. Online Platform and Its Impacts. Online platforms that are constructed based on emerging technologies bring many benefits. For example, P2P platforms such as eBay, Uber and Airbnb promote matching between the seller and the buyer by using their advanced algorithms [14]. Many platforms can reduce market failure by using advanced search and matching algorithms [15]. The platform can increase the transparency of transactions by reducing information asymmetry [16], and the platform can reduce transaction friction by increasing the transparency of price information [17].

An issue that has been emphasized by scholars is the impact of Internet-based platforms on traditional industries. In the hotel industry, there is evidence that the increasing supply of Airbnb had a significant negative impact on the revenue of the traditional hotel industry [18]. Dogru et al. supported this view by finding that the increased supply of Airbnb had a negative impact on room revenue, average daily rate, and occupancy in the traditional hotel industry [19]. However, another study found that Airbnb had no significant impact on traditional hotel occupancy and turnover in several cities in the United States [20].

As for the transportation industry, many scholars found the emergence of ride-hailing services had a significant influence on traditional travel modes. However, scholars have not reached a consensus. For example, Clewlow and Mishra studied the impact of Uber on urban transportation in the United States and found that Uber could reduce the use of public transit by $6 \%$ when all other things are equal [21]. However, empirical work by Hall et al. found that Uber had a complementary effect on the use of public transit in American cities [22]. Berger et al. showed that ride-hailing services shocked the traditional taxi industry, and they found that the introduction of Uber into cities reduced the income of taxi drivers by approximately 10\% [23]. However, Wallsten et al. showed that ride-hailing services brought benefits to taxi industry. They found that after Uber entered cities, the traditional taxi industry was forced to passively improve service quality, and the number of passenger complaints significantly decreased [24].

Many studies have touched upon the impact of ridehailing on the use of private cars. Some scholars believe that ride-hailing will substitute the use of private cars. Vanderschurenden et al. found that, in Cape Town, more and more people are using ride-hailing instead of using a private 
car, and some of them gave up ownership of private cars [2]. Ward et al. estimated the impact of the entry of Uber and Lyft into cities in U.S. on local private cars per capita via a difference-in-differences method. The research results showed that the introduction of Uber reduced local private cars per capita by $2.8 \%$ in the first two years after its entry into cities, whereas Lyft reduced local per capita private car ownership by $4.6 \%$ in the first two years after its entry into cities [9]. However, other scholars believe the emergence of ride-hailing services in a city may increase the number of private cars. Guo et al. found that, due to the low threshold, high income, and free time to participate, many people consider buying a new car to engage in ride-hailing services, thus increasing the ownership of private cars [25]. Gong et al. believe that the flexible work schedule and earning additional income through sharing excess capacity have attracted many private car drivers to join ride-hailing services, thus increasing the use of private cars [13].

2.2. Rational Choice Theory and Prospect Theory. In this section, we refer to the existing literature to analyze how travelers choose between private cars and ride-hailing. The choice of individual travel mode is influenced by various factors such as travel cost, travel purpose and travel time $[26,27]$. Travelers' choice between private car and ridehailing needs to be analyzed at the psychological level. The choice of travel mode is unpredictable because of risk and uncertainty of information [28]. At the same time, travelers always want to maximize their own interests when they travel. Therefore, we need to combine rational choice theory with prospect theory to comprehensively analyze travelers' choice between private cars and ride-hailing.

Rational choice theory has evolved from a classical economic paradigm (based on the "hypothesis of economic man") to a modern, nonmainstream economics paradigm (based on the "hypothesis of the limited rationality actor"). According to rational choice theory, no matter how it has evolved, maximization of individual utility is always the decision-maker's principal aim [29]. The rational choice theory of classical economics takes the "economic man hypothesis" as the premise and "complete information and complete rationality" as the background and pursues utility maximization under the condition of cognitive determination [30]. Therefore, the rational choice theory in the classical economics paradigm is similar to expected utility theory. Rational choice theory in a modern, nonmainstream economics paradigm takes the "limited rational actor hypothesis" as the premise, which states that "bounded information and bounded rationality" are the background, and this means that individuals pursue self-interest under the condition of cognitive uncertainty [31]. In this way, it can objectively and truly analyze the psychological and behavioral performance of people in real life. In the context of the rise of ride-hailing platforms, travelers will make rational decisions based on cost comparison (e.g., the cost of ridehailing and time delay vs. the cost of owning a private car) $[32,33]$.To increase market share, ride-hailing platforms are devoted to reducing travelers' ride-hailing costs by providing discount prices and employing many of vehicles. These efforts have attracted plenty of passengers.

However, people are not always rational when they make decisions. When people are disturbed by many factors, they often make irrational decisions [34]. Prospect theory can help to explain people's irrational behavior in uncertain situations [35]. Prospect theory mainly describes different reactions to gain and loss in the same environment [36]. It is mainly explained by three effects: certainty effect, frame effect, and endowment effect [37-39]. A certainty effect means that people tend to overestimate certain results and underestimate uncertain results in the decision-making process. The certainty effect primarily acts by promoting risk-aversion under the condition of gain and risk-seeking under the condition of loss. The endowment effect means that people give better appraisal to what they own than what others own. The main manifest is that people's pain for the loss of something is greater than their happiness for the gain of something. The framing effect is mainly manifested in that people tend to avoid risks in a positive frame (i.e., a gain) but seek risks in a negative frame (i.e., a loss). In the context of the rise of ride-hailing platforms, ride-hailing has undoubtedly become an important mode of transportation. Then, how will travelers choose between private cars and ride-hailing? The prospect theory can help to analyze this question. For example, according to the certainty effect, the traveler's sense of certainty is usually based on tangibility rather than functionality. Even private cars and ride-hailing have the same functionality, travelers think that private cars have greater certainty than ride-hailing. Therefore, the value of private cars, which are tangible, is overestimated, and the value of ride-hailing with the same travel functionality is underestimated [40].

Detailed analyses based on these two theories are given in Section 4 to explain the findings.

\section{Empirical Test Design}

3.1. Natural Experiment and Analysis Model. Market entry of ride-hailing services (such as Uber and Didi) into different cities in China varies over time, which provides us an opportunity to do a natural experiment. Both Uber and Didi started their ride-hailing services in China's major cities in 2014, and their share of the Chinese market has risen rapidly due to their strong capital backing. According to a report on China's ride-hailing market released by Analysys, which is a commercial information service platform based on the research results of new media economy (internet, mobile internet, telecom, etc.), Uber and Didi are the top two companies in China's ride-hailing rental market, and their market share totals $93.1 \%$ in 2015. After the merger of Didi and Uber in 2016, Didi has occupied more than $90 \%$ of China's ride-hailing market. The merger of Didi and Uber in China triggered the market to ride-hailing industry monopoly concerns (for more details, refer to http://finance. ifeng.com/a/20160804/14684740_0.shtml (in Chinese)). Therefore, Didi and Uber can be viewed as representative of the whole ride-hailing industry in China. Although a small number of ride-hailing services entered Chinese cities before 
2014, the scale was too small to have a significant impact on urban transport. Uber was launched in Beijing, Shanghai, Guangzhou, Shenzhen, Chongqing, Chengdu, and Hangzhou in 2014, and Didi started operating in Beijing in 2014. After this, ride-hailing services in China have had a great momentum. At the end of 2013, there were only 32 million ride-hailing users in China. However, in 2014, there were 211 million ride-hailing users in China, and after 2015, the number stabilized to approximately 300 million, according to Speed Transit Research Institute: Ride-Hailing Market Research Report in 2017 (available at: http://www.sootoo. com/content/675157.shtml (in Chinese)). We designed a natural experiment based on the time heterogeneity of ridehailing services entering different cities.

We used a time window of seven years, from 2010 to 2016, for the research. Ride-hailing services such as Didi Chuxing and Uber were introduced to cities in 2014. We analyzed the impact of ride-hailing services on private car use in urban areas in the year when a ride-hailing service entered the cities and the next two years after a ride-hailing service entered the city. By the end of 2016, there were still many cities in China that had not been introduced to ridehailing services. We were able to construct a comparable experimental group (cities with ride-hailing services) and a control group (cities with no ride-hailing services) by closing the research time window in 2016. China's ride-hailing services are being promoted in cities at a relatively rapid rate. By the end of 2017, China's major cities were basically covered by ride-hailing services, while only a small number of small cities had not been introduced to ride-hailing services. If we had included the years after 2016 in our sample, we would have been unable to construct comparable experimental and control groups. Therefore, we chose 2010-2016 as the time window of the research. This decision may have affected our exploration of the long-term effects of the introduction of ride-hailing, but considering the rapid development of ride-hailing, the dynamic effect of a platform's entry into a city for two years can also help us understand its relatively "long-term" effect.

In 2014, only seven cities, Beijing, Shanghai, Guangzhou, Shenzhen, Chongqing, Chengdu, and Hangzhou, had been introduced to large-scale ride-hailing services. Therefore, we included these seven cities in the experimental group. The characteristics of these cities (in 2014, 2015, and 2016) are shown in Table 1 . In these cities, there were no large-scale ride-hailing services from 2010 to 2013, and there were largescale ride-hailing services from 2014 to 2016. We selected cities with no large-scale ride-hailing services during the whole sample study period (2010-2016) as the control group. After a careful search of relevant information, we selected a total of 102 cities that had no ride-hailing services before 2017 to form a control group. See Table 2 for the list of control cities.

After controlling other factors that may affect the use of private cars in urban areas, we applied the difference-indifferences method to estimate the impact of the entry of ride-hailing services on the use of private cars in urban areas. To construct the difference-in-differences model, we set up two dummy variables. For those cities that had ride- hailing services in 2014, the dummy variable TREATED was assigned a value of 1 , and otherwise, it was assigned a value of 0 . The other dummy variable $T$ was assigned a value of 1 in the year when the ride-hailing services entered the experimental city and the following years. $T$ was assigned a value of 0 before the ride-hailing services entered the experimental city. Therefore, the samples can be divided into four groups: control group before ride-hailing services entered the city $(T R E A T E D=0, T=0)$, control group after ride-hailing services entered the city (TREATED $=0, T=1)$, experimental group before ride-hailing services entered the city $(T R E A T E D=1, T=0)$, and experimental group after the ride-hailing services entered the city ( TREATED =1, T=1). The econometric model is as follows:

$$
\begin{aligned}
\text { PCO }_{i t}= & \beta_{0}+\beta_{1} \text { TREATED }_{i}+\beta_{2} T_{t}+\beta_{3} \text { TREATED }_{i} \times T_{t} \\
& +\beta_{4} \text { CONTROL }_{i t}+\mu_{i}+\lambda_{t}+\varepsilon_{i t} .
\end{aligned}
$$

The concept we were concerned with in this paper was the use of private cars. However, it is difficult to collect data on private cars use in our sample cities, so we used a proxy variable to indicate this concept. The use of private cars mainly depends on private car ownership [41, 42], and it is less likely to be affected by other factors (e.g., built environment, travel distance, and travel purpose) [43-45]. Studies have shown that private cars are very appealing to people. Once people own a private car, their use of it will increase [43, 46], leading to the formation of a habit [47-49]; this habit will result in exclusive travel behavior.

After this habit is reinforced, people who own private cars will use them exclusively, and their frequency of using other modes of travel will be lower $[50,51]$; almost no other modes of travel will be used [52]. Therefore, private car ownership and private car use in cities are highly positively correlated. Previous studies have adopted private car ownership as a proxy variable for private car usage [53, 54], and this article follows this method. Therefore, we chose $P C O_{i t}$, private car ownership in city $i$ in year $t$, to measure private car use. The coefficients of TREATED $D_{i}$ and $T_{t}$ will be absorbed by individual fixed effects and time fixed effects, respectively. This paper cares most about the interaction between TREATED and T, TREATED $\times T$. Its coefficient $\beta_{3}$ measures the net effect of the entry of ride-hailing services on the use of private cars in urban areas.

$\mathrm{CONTROL}_{i t}$ is a set of control variables that will be described in the next section. $\mu_{i}$ is the individual effect, $\lambda_{t}$ is the time effect, and $\varepsilon_{i t}$ indicates the error term. This paper uses clustered robust standard errors to solve the potential problems of sequence autocorrelation and heteroscedasticity. A two-way fixed effect model including individual effects and time effects needed to be adopted to reduce the interference of the individual effect and time effect on the analysis.

3.2. Control Variables. We controlled for several variables that could affect the use of private cars in urban areas, which mainly includes socioeconomic indicators, transport-related indicators, and number of mobile telephone subscribers. 
TABLE 1: Related indicators of the experimental group.

\begin{tabular}{|c|c|c|c|c|c|c|c|c|}
\hline \multirow{2}{*}{ Year } & \multirow{2}{*}{ Indicator } & \multicolumn{7}{|c|}{ City } \\
\hline & & Beijing & Shanghai & Guangzhou & Shenzhen & Chongqing & Chengdu & Hangzhou \\
\hline \multirow{3}{*}{2014} & Private cars ownership (unit) & 4372000 & 1834300 & 1792505 & 2639166 & 1900000 & 2800000 & 1799400 \\
\hline & Population density (person/sq $\cdot \mathrm{km}$ ) & 812.5 & 2269.23 & 1133.2 & 1663.55 & 363.6 & 998.88 & 431.28 \\
\hline & Per capita GDP (yuan) & 99995 & 97370 & 128478 & 149495 & 47850 & 70019 & 103813 \\
\hline \multirow{3}{*}{2015} & Private cars ownership (unit) & 4403000 & 2087100 & 1806508 & 2679280 & 2300000 & 3300000 & 1800000 \\
\hline & Population density (person/sq.km) & 819.57 & 2275.67 & 1148.78 & 1777.67 & 366.5 & 1013.12 & 436.25 \\
\hline & Per capita GDP (yuan) & 106479 & 103796 & 136188 & 157985 & 52322 & 74273 & 112230 \\
\hline \multirow{3}{*}{2016} & Private cars ownership (unit) & 4528000 & 2427100 & 1848977 & 2650617 & 2800000 & 3700000 & 1826500 \\
\hline & Population density (person/sq.km) & 830.5 & 2282.11 & 1170.3 & 1927.9 & 369.9 & 975.9 & 433.5 \\
\hline & Per capita GDP (yuan) & 118198 & 116562 & 141933 & 167411 & 57904 & 76960 & 124286 \\
\hline
\end{tabular}

TABLE 2: Control group cities.

\begin{tabular}{cc}
\hline Control group \\
\hline Xandong, Yingkou, Panjin, Chaoyang, Liaoyang, Fuxin, Benxi, Tieling, Huludao, Chuzhou, Bengbu, Ma'anshan, Suzhou, \\
Xuancheng, Tongling, Huainan, Chizhou, Anqing, Bozhou, Baoding, Cangzhou, Xingtai, Qinhuangdao, Hengshui, Weifang, \\
Zibo, Zaozhuang, Heze, Rizhao, Liaocheng, Lianyungang, Zhenjiang, yancheng, Taizhou, Pingdingshan, Shangqiu, Xinxiang, \\
Luohe, Sanmenxia, Zhoukou, Anyang, Hebi, Xinyang, Nanyang, Xinzhou, Changzhi, Yangquan, Jinzhong, Jincheng, Linfen, \\
City \\
nonghua, Songyuan, Baicheng, Baishan, Jilin, Jieyang, Chaozhou, Shaoguan, Yangjiang, Guigang, Hechi, Liuzhou, Chongzuo, \\
Fangchenggang, Qinzhou, Baise, Ordos, Wulanchabu, Yingtan, Ganzhou, Jingdezhen, Fuzhou, Jian, Zhangzhou, Zhangjiajie, \\
Yongzhou, Huaihua, Hengyang, Yueyang, Chenzhou, Lishui, Guangan, Ningde, Longyan, San Ming, Daqing, Suihua, Hegang, \\
Lijiang, Qujing, Baoshan, Lincang, Liupanshui, Anshun, Baoji, Ankang, Hanzhong, Tianshui, Qingyang, Longnan, Xianning,
\end{tabular}
Huanggang

Many socioeconomic indicators of the city have been verified having significant influences on the use of private cars in urban areas. These indicators include the average wage of employed workers $[55,56]$, number of employed persons [57], number of unemployed persons [58], population density [59, 60], per capita GDP [61, 62], GDP growth rate [63], and the number of college students $[64,65]$.

Some transport-related indicators also influence the use of private cars in cities, which include miles on the metro [66], number of public transit vehicles per 10,000 people $[67,68]$, number of taxis [69], and total area of urban roads [55].

The number of mobile telephone subscribers is related to the degree of informatization, modernization, and economic development of a city [70]. We also included it as a control variable.

All variables were treated logarithmically except the use of private cars, miles of metro, and GDP growth rate. The data used in this paper came from the global statistical analysis platform of the Economy Prediction System (in Chinese). A few missing data were filled from The Statistical Yearbook of Prefecture-level Cities (in Chinese). All experimental data were annual. The definitions and descriptive statistics of the variables are shown in Table 3.

\section{Empirical Analysis}

4.1. Multicollinearity Test. There may be multicollinearity among the control variables. The multicollinearity test results are shown in Appendix Table 4. All VIF values are less than 10. Therefore, we can say that there is no multicollinearity in this study.

4.2. The Average Impact of Ride-Hailing Services on Private Car Use in Urban Areas. According to (1), the logarithm of the use of private cars in urban areas is the outcome variable for the test, and the results are shown in Table 5. Column (1) of Table 3 shows the regression results without adding control variables, and column (2) of Table 3 shows the regression results after adding control variables. In the model without control variables, the DID coefficient $(T \times T R E A T E D)$ is -0.1325 , which is statistically significant at the $10 \%$ level. After controlling for the impacts of socioeconomic and transport heterogeneity between cities, the DID coefficient $(T \times T R E A T E D)$ is -0.0869 , which is statistically significant at the $10 \%$ level. The results suggest that the use of private cars in the experimental cities decreased by about $9 \%$ in the year when ride-hailing services entered the cities. This result excludes the impact of all control variables and the impact of time. It is the net impact of a ride-hailing service entering the city on the use of private cars in urban areas.

In addition, in the regression results presented in column (2) of Table 5, the coefficients of socioeconomic indicators such as $L n A W E, \operatorname{LnNEP}$, LnPD, and LnPCGDP are all significantly positive. This indicates that the higher the average wage of employed workers is, the more the likely employed persons can afford to buy private cars and the more the people will thus use private cars to travel. The number of employed persons will have a positive impact on the use of private cars. A private car is an important and 
TABle 3: Definition and descriptive statistics of the main variables.

\begin{tabular}{|c|c|c|c|c|c|c|c|}
\hline & Variable & Description & Unit & Mean & $\begin{array}{l}\text { Std. } \\
\text { dev. }\end{array}$ & Min & Max \\
\hline $\begin{array}{l}\text { Explained } \\
\text { variable }\end{array}$ & LnPCO & Private car ownership & (unit) & 12.2525 & 0.9822 & 9.0156 & 15.3258 \\
\hline \multirow[b]{2}{*}{$\begin{array}{l}\text { Explanatory } \\
\text { variables }\end{array}$} & $\mathrm{T}$ & $\begin{array}{l}\text { Year dummy, 2010-2013 is assigned a value } \\
\text { of } 0 \text {, and 2014-2016 is assigned a value of } 1 .\end{array}$ & $(/)$ & 0.0275 & 0.1637 & 0 & 1 \\
\hline & TREATED & $\begin{array}{l}\text { City dummy, cities with ride-hailing entry } \\
\text { are assigned a value of } 1 \text {, otherwise } 0 .\end{array}$ & $(/)$ & 0.0642 & 0.2453 & 0 & 1 \\
\hline \multirow{13}{*}{$\begin{array}{l}\text { Control } \\
\text { variables }\end{array}$} & TREATED $\times T$ & Difference-in-differences term & $(/)$ & 0.0275 & 0.1637 & 0 & 1 \\
\hline & LnAWE & The average wage of employed workers & (Yuan) & 10.6402 & 0.2929 & 9.9236 & 11.7179 \\
\hline & LnNEP & Number of employed persons & (1000 persons) & 3.5147 & 0.8439 & 1.96 & 6.6739 \\
\hline & LnNUP & Number of unemployed persons & (Person) & 8.7952 & 1.1017 & 5.786 & 12.6639 \\
\hline & LnPD & Population density & $\begin{array}{l}\text { (Person/ } \\
\text { sq.km) }\end{array}$ & 5.7356 & 0.8235 & 2.8639 & 7.7328 \\
\hline & LnPCGDP & Per capita GDP & (Yuan) & 10.4539 & 0.5609 & 8.7028 & 12.2806 \\
\hline & GDPGR & GDP growth rate & $(\%)$ & 10.1096 & 4.3123 & -12.3 & 22.5 \\
\hline & LnNCS & The number of college students & (Person) & 1.0463 & 1.236 & -2.4079 & 4.6608 \\
\hline & ML & Miles on the metro & $(\mathrm{km})$ & 15.0489 & 74.6292 & 0 & 614.23 \\
\hline & LnPTVPER10000 & $\begin{array}{l}\text { Number of public transit vehicles per } 10000 \\
\text { people }\end{array}$ & (unit) & 1.7669 & 0.7836 & -1.1394 & 4.7051 \\
\hline & LnNT & The number of taxis & (unit) & 7.3147 & 1.0778 & 4.4067 & 11.1343 \\
\hline & LnRA & The total area of urban roads & $(10000 \mathrm{~m} 2)$ & 6.7928 & 0.9405 & 4.1588 & 9.7856 \\
\hline & LnNMP & Number of mobile telephone subscribers & $\begin{array}{c}(10000 \\
\text { subscribers })\end{array}$ & 5.6315 & 0.7865 & 3.658 & 8.3129 \\
\hline
\end{tabular}

TABLE 4: Multicollineraity analysis results.

\begin{tabular}{lcc}
\hline Variables & VIF & $1 /$ VIF \\
\hline LnPTVPER10000 & 1.91 & 0.522305 \\
LnCOLLEGE & 2.95 & 0.339406 \\
LnNEP & 9.43 & 0.106064 \\
LnNMP & 7.07 & 0.141526 \\
LnRA & 5.37 & 0.186358 \\
LnAWE & 2.78 & 0.359586 \\
LnNT & 3.52 & 0.284127 \\
ML & 2.22 & 0.449716 \\
LnNUP & 2.87 & 0.348012 \\
LnPCGDP & 3.25 & 0.307604 \\
LnPD & 1.67 & 0.599565 \\
GDPGR & 1.38 & 0.722834 \\
VIF mean & & \\
T*TREAT & 3.70 & - \\
\hline
\end{tabular}

luxurious means of commuting, and when people are employed, their economic status is usually good. Therefore, the greater the number of employed people in a city is, the greater the number of people who will use private cars. The greater the urban population density is, the higher the degree of urbanization is, and the wealthier the citizens are, the more the likely the citizens are to use private cars to travel. Some studies have found that high-density population areas have a lower usage rate for urban private cars [71-73], and an increased usage rate for public transportation as well as for walking and cycling. However, we examined the effect of population density on private car use at the city level, rather than in specific areas of the city only (e.g., the CBD). This finding supports the research of Guo et al. [25], Guo et al. [74], and Guo et al. [75], who also find that the urban population has a significant positive impact on new car sales.
TABLE 5: Average impact of ride-hailing services on private car use in urban areas.

\begin{tabular}{lcc}
\hline \multicolumn{2}{c}{$\begin{array}{c}\text { Explained variable: the logarithmic transformation of private car } \\
\text { usage }\end{array}$} & $(2)$ \\
\hline & $(1)$ & $-0.0869^{*}(0.045)$ \\
DID (TREATED $\times$ T) & $0.0074^{* * *}(0.0017)$ \\
LnAWE & $0.1451^{* *}(0.0685)$ \\
LnNEP & $-0.0422^{*}(0.0214)$ \\
LnNUP & $0.4903^{*}(0.2905)$ \\
LnPD & $0.0366^{* * *}(0.0109)$ \\
LnPCGDP & $0.0064(0.0041)$ \\
GDPGR & & $0.0087(0.0569)$ \\
LnNCS & & $-0.0005^{* * *}$ \\
ML & & $(0.0001)$ \\
& & $-0.0008^{* * *}$ \\
LnPTVPER10000 & & $(0.0003)$ \\
& & $-0.0781^{* * *}$ \\
LnNT & & $(0.0203)$ \\
LnRA & & $0.0428(0.071)$ \\
LnNMP & & $0.1909^{* *}(0.084)$ \\
City fixed impacts & & Yes \\
Time fixed impacts & Yes & Yes \\
Clustered on city & Yes & Yes \\
Constant & $11.7516^{* * *}$ & $13.6569^{* * *}(2.802)$ \\
R-squared & $(0.0198)$ & $0.78($ within $)$ \\
Number of & 0.76 (within) & 763 \\
observations & 763 &
\end{tabular}

$p$ value, ${ }^{*} p<0.1 ;{ }^{* *} p<0.5 ;{ }^{* * *} p<0.1$. Robust standard errors in parentheses (clustered by city).

The higher the per capita GDP, the more developed the city, the higher the living standards of the residents, and the more 
the people who use private cars. Therefore, the per capita GDP will have a positive impact on the use of private cars. The coefficients of $L n N U P$ are all significantly negative, indicating that the number of unemployed persons in cities will have a negative impact on the use of private cars. Private cars are an important and luxurious means of commuting. The use of private cars for travel requires a certain degree of financial well-being. People who are unemployed usually have poorer economic conditions than those who are employed. Therefore, the greater the number of unemployed persons in a city is, the fewer the people who use private cars are. The coefficients of transport-related indicators such as $M L, L n P T V P E R 10000$, and $L n N T$ are all significantly negative, indicating that miles traveled on the metro, urban public transit development level, and number of taxis will all have negative impacts on the use of private cars. That is, use of the metro, public transit, and taxis will compete with private car use. The coefficient of $\operatorname{LnNMP}$ is significantly positive, indicating that the greater the number of mobile telephone subscribers in a city, the more the people who use private cars. The number of mobile telephone subscribers reflects the degree of informatization of a city, so it is no surprise that there is a positive relationship between the number of mobile telephone subscribers and the usage of private cars.

In summary, the main control variables are significant and in line with expectations, which to a certain extent illustrates the rationality of the model built.

\subsection{The Dynamic Effect of Ride-Hailing Services on Private Car} Use in Urban Areas. Table 5 shows the average impact of ride-hailing services on private car use in urban areas. Next, we use (2) to estimate the continuous impact on the use of private cars in urban areas after ride-hailing services entered the city:

$$
\begin{aligned}
\text { PCO }_{i t}= & \beta_{0}+\beta_{1} \text { TREATED }_{i}+\beta_{2} T_{t}+\beta_{\text {post }} \text { TREATED }_{i} \\
& \times T_{t}^{\text {post }}+\beta_{4} \text { CONTROL }_{i t}+\mu_{i}+\lambda_{t}+\varepsilon_{i t} .
\end{aligned}
$$

The difference between (2) and (1) is that $T_{t}^{\text {post }}$ is the dummy variable in the year after ride-hailing services enter a city. Post $=1$ represents the first year after the ride-hailing services enter the city (in 2015). Post $=2$ refers to the second year after the ride-hailing services enter the city (in 2016). $\beta_{\text {post }}$ measures the impact of ride-hailing services on private car use in urban areas in the year after they enter cities.

In Table 6, regardless of whether control variables are added, the coefficient of TREATED ${ }_{i} \times T_{t}^{\text {post }}$ is significant and negative, which indicates that the use of private cars in urban areas is significantly reduced after ride-hailing services enter the city. As time goes by, the coefficient of TREATED $_{i} \times T_{t}^{\text {post }}$ initially increases and then decreases. The negative impact of ride-hailing services on private car use in urban areas initially strengthens and then weakens. Specifically, in 2015, the first year after ride-hailing services entered the city, the use of private cars in urban areas in the experimental group is reduced by $11.52 \%$. In the second year
TABle 6: Dynamic effect of hailing services on the use of private cars urban areas.

Explained variable: the logarithmic transformation of private car usage

\begin{tabular}{lcc}
\hline & $(1)$ & $(2)$ \\
TREATED $\times T^{1}$ & $-0.1456^{*}(0.079)$ & $-0.115^{*}(0.066)$ \\
TREATED $\times T^{2}$ & $-0.1132^{*}(0.0639)$ & $-0.0416^{* *}(0.02)$ \\
Control variables & No & Yes \\
City fixed impacts & Yes & Yes \\
Time fixed impacts & Yes & Yes \\
Clustered on city & Yes & Yes \\
Constant & $12.12^{* * *}(0.012)$ & $16.6422^{* * *}(2.9151)$ \\
R-squared & 0.63 (within) & 0.66 (within) \\
Number of observations & 763 & 763 \\
\hline
\end{tabular}

$p$ value, ${ }^{*} p<0.1 ;{ }^{* *} p<0.5 ;{ }^{* * *} p<0.1$. Robust standard errors in parentheses (clustered by city).

after ride-hailing services entered the city, the use of private cars in urban areas in the experimental group was reduced by $4.16 \%$.

It is easy to conclude that the entry of ride-hailing services significantly reduces the use of private cars in urban areas from the previously mentioned research results. Due to the convenience and flexibility of ride-hailing services and the fact that there is no maintenance fee or parking fee, some citizens delay or give up purchasing private cars. In our sample cities, the use of private cars decreases by $4-11.5 \%$ in the two years after ride-hailing services entered the cities. That change is enough to draw the attention of car dealers, city environmental regulators, and urban transportation administrators.

\section{Robustness Test}

5.1. Parallel Trend Test. To ensure the validity of the evaluation results obtained by the difference-in-differences method, we must meet an important prerequisite. Before the "experimental shock," the use of private cars in the experimental and control cities must show the same trend over time (meet the parallel trend $[76,77]$ ). For this purpose, we drew a chart of the use of private cars in the experimental group and the control group from 2010 to 2016 (Figure 1). Figure 1 shows that, before ride-hailing services entered the city, the change in the use of private cars in the experimental group city and the control group city was the same (the use of private cars in urban areas increased considerably). However, after ride-hailing services entered the experimental group, the increase in private car use in the experimental group slowed down significantly. The use of private cars in the control group maintained the previous growth trend to a large extent. Therefore, we can say that the difference-in-differences model used in this paper conforms to the parallel trend hypothesis.

5.2. Robustness Test Based on PSM-DID. All cities in the experimental group are large cities, but in control groups there are some middle-sized cities. This may lead to bias. We employed the method which integrates propensity score 


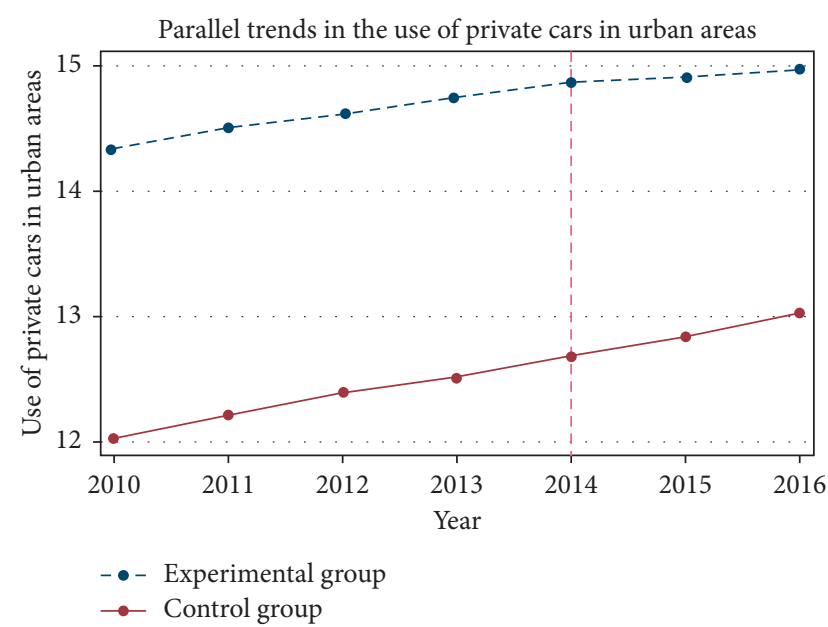

FIGURE 1: Parallel trend test of private car use in experimental and control groups.

matching with difference-in-differences method (PSM-DID) to test the robustness of the results obtained by the difference-in-differences method [78, 79].

The main idea of propensity score matching (PSM) is to find city $j$ in the control group and make it as similar as possible to city $i$ in the experimental group, that is, $x_{i}=x_{j}$. When the entry of ride-hailing services in a city can be determined by observable variables, the probability of the entry of ride-hailing services in city $j$ and city $i$ is similar. However, there are also some limitations. If there are an excessive number of matching variables, it will require highdimensional space for matching. This demand may cause data sparseness and made it difficult to find $x_{j}$ that is close to $x_{i}$. If there are too few matching variables, an inappropriate control group of cities may be generated. PSM calculates the propensity score $p$ according to the multidimensional matching index and matches them according to the similarity of $p$ values between the experimental group and the control group. The propensity score $p$ is a one-dimensional variable between 0 and 1 , which can better solve the previously mentioned problems.

Before using PSM-DID for the robustness test, this paper estimated the propensity score $p$ using a Logit model and used the kernel matching method for matching. PSM requires that there are no significant differences in observable variables between the matched experimental group and the control group. If there is a significant difference between the experimental group and the control group, it indicates that the kernel matching estimation is not effective. Therefore, this paper carried out the matching balance test before reporting the results. The results are displayed in Table 7 of the appendix. After matching, the standard deviation between the experimental group and the control group on urban characteristics such as the number of public transportation units per 10,000 and GDP growth rate was significantly reduced, and the absolute value of the standard deviation was less than $10 \%$, which indicates that PSM can greatly reduce the differences between experimental and control groups. In addition, the absolute value of the $T$ test was significantly smaller, which means that the difference in covariates between the two groups after matching was further reduced. The results showed that there was no systemic difference between the experimental group and the control group after matching. Therefore, PSM-DID can be used for robustness tests in this paper.

We used PSM-DID to check the robustness of the preliminary results. First, the PSM was used to select the experimental group and the control group with similar characteristics in all aspects of the observable variables. Then, the difference-in-differences method was used to examine the impact of ride-hailing services on the use of private cars in urban areas after PSM matching. The results in Table 8 show that the use of private cars in experimental cities decreased by $19.27 \%$ in the year when ride-hailing services entered the cities. This finding revealed that the impact of ride-hailing services on private car use was much larger (compared to the results in Table 3) after the systematic differences between the experimental and control cities were excluded. This section may be divided by subheadings. It should provide a concise and precise description of the experimental results, their interpretation, and the experimental conclusions that can be drawn.

5.3. Counterfactual Tests. We conducted a counterfactual test by changing the time that ride-hailing services entered the experimental city. We assumed that the time for ridehailing services entering the experimental city was advanced by two or three years. If the coefficient of TREATED $\times T$ is significant and negative, it indicates that the decrease in the use of private cars in urban areas is caused by other random factors, and the conclusion that ride-hailing services have a negative impact on the use of private cars in urban areas is probably not valid. The estimated results in Table 9 show that after the time for ride-hailing services entering the experimental city was advanced by two or three years, the coefficient of TREATED $\times T$ was not significant and negative. This finding verifies that the decrease in the use of private cars in urban areas was not caused by other random factors.

5.4. Control Variables Lag by One Period. There may be inverse relationships between the selected variables and ridehailing services entering a city, which may cause an endogeneity problem. To settle this problem, we lagged the selected controls for one period and conducted regression again. The results are shown in Table 10. It can be seen from Table 7 that the main results are not qualitatively different from those in Table 3. The robustness of the preliminary results is further demonstrated.

\section{Heterogeneity of Urban Location}

In China, the development of eastern cities is generally better than that of western cities. Does the impact of ride-hailing services also differ in eastern and western cities? From an empirical perspective, we analyzed the negative impact of ride-hailing services on the use of private cars in different urban locations. 
TABLe 7: Propensity score matching balance test results (2010-2016).

\begin{tabular}{|c|c|c|c|c|c|c|c|}
\hline \multirow{2}{*}{ Variable name } & \multirow{2}{*}{ Samples } & \multicolumn{2}{|c|}{ Mean difference } & \multicolumn{2}{|c|}{ Standardized difference } & \multirow{2}{*}{$T$ value } & \multirow{2}{*}{$p$ value } \\
\hline & & Experimental group & Control group & Standardized difference & Decreasing range & & \\
\hline \multirow{2}{*}{ PTVPER10000 } & Prematch & 27.393 & 12.53 & 90.3 & 95.5 & 5.92 & 0.001 \\
\hline & Postmatch & 6.9229 & 13.441 & -4.0 & & -0.09 & 0.939 \\
\hline \multirow{2}{*}{ GDPGR } & Prematch & 10.237 & 10.237 & 12.3 & 83.7 & 0.26 & 0.796 \\
\hline & Postmatch & 9.768 & 10.161 & 2.0 & & 0.06 & 0.950 \\
\hline
\end{tabular}

TABLE 8: Robustness test based on PSM-DID.

Explained variable: the logarithmic transformation of private car usage

(1)

(2)

\begin{tabular}{lcc}
\hline DID $($ TREATED $\times T)$ & $-0.2223^{*}(0.1235)$ & $-0.1927^{*}(0.1157)$ \\
Control variables & No & Yes \\
City fixed impacts & Yes & Yes \\
Time fixed impacts & Yes & Yes \\
Clustered on city & Yes & Yes \\
Constant & $11.8779^{* * *}(0.0242)$ & $16.7197^{* * *}(2.4764)$ \\
R-squared & 0.85 (within) & 0.89 (within) \\
Number of observations & 238 & 238 \\
\hline
\end{tabular}

$p$ value, ${ }^{*} p<0.1 ;{ }^{* *} p<0.5 ;{ }^{* * *} p<0.1$. Robust standard errors in parentheses (clustered by city).

TABLe 9: Counterfactual test.

\begin{tabular}{lcc}
\hline & Explained variable: the logarithmic transformation of private car usage & 2012 \\
\hline DID (TREATED $\times T)$ & 2011 & $-0.0774(0.0565)$ \\
Control variables & $-0.047(0.038)$ & Yes \\
City fixed impacts & Yes & Yes \\
Time fixed impacts & Yes & Yes \\
Clustered on city & Yes & Yes \\
Constant & Yes & $8.8253^{* * *}(3.0212)$ \\
R-squared & $12.5053^{* * *}(4.055)$ & $0.82($ within) \\
Number of observations & 0.76 (within) & 763 \\
\hline
\end{tabular}

$p$ value, ${ }^{*} p<0.1 ;{ }^{* *} p<0.5 ;{ }^{* * *} p<0.1$. Robust standard errors in parentheses (clustered by city).

The experimental cities of Beijing, Shanghai, Guangzhou, Shenzhen, and Hangzhou are located in east of China, whereas Chengdu and Chongqing are western cities. Therefore, we analyzed the impact of ride-hailing services on the use of private cars in eastern and western cities, respectively. The results are shown in Table 11. It can be seen from Table 11 that, whether control variables are included or not, ride-hailing services in eastern cities had a negative impact on the use of the private cars. Without adding control variables, ride-hailing services in western cities had a positive impact on the use of the private cars. After adding control variables, ride-hailing services in western cities had no significant influence on the use of the private cars. Specifically, ride-hailing services in eastern cities reduced the use of the private cars by $14.78 \%$, but in western cities it had no significant impact on the use of the private cars. This conclusion confirms the hypothesis that the impact of ride-
TABLE 10: Regression results of all control variables lagged for one period.

Explained variable: the logarithmic transformation of private car usage

\begin{tabular}{lc}
\hline DID $($ TREATED $\times T)$ & $-0.1428^{* *}(0.062)$ \\
All control variables lag for one period & Yes \\
City fixed impacts & Yes \\
Time fixed impacts & Yes \\
Clustered on city & Yes \\
Constant & $11.93^{* * *}(0.144)$ \\
R-squared & 0.72 (within) \\
Number of observations & 642 \\
\hline
\end{tabular}

$p$ value, ${ }^{*} p<0.1 ;{ }^{* *} p<0.5 ;{ }^{* * *} p<0.1$. Robust standard errors in parentheses (clustered by city).

hailing services on the use of private cars in urban areas is heterogeneous according to city location. 
TABLE 11: Analysis of urban location heterogeneity.

Explained variable: the logarithmic transformation of private car usage

Eastern city

Western city

(1) (2)

$\begin{array}{cc}-0.2372^{* * *}(0.0684) & -0.1478^{* *}(0.0626) \\ \text { No } & \text { Yes } \\ \text { Yes } & \text { Yes } \\ \text { Yes } & \text { Yes } \\ \text { Yes } & \text { Yes } \\ 11.7039^{* * *}(0.0199) & 13.8621^{* * *}(2.8086) \\ 0.76 \text { (within) } & 0.78 \text { (within) } \\ 749 & 749\end{array}$

$0.1297^{*}(0.0702)$
No
Yes
Yes
Yes
$11.6352^{* * *}(0.0203)$
0.77 (within)
728

DID (TREATED $\times T$ )

Control variables

City fixed impacts

Time fixed impacts

Clustered on city

Constant

R-squared

Number of observations

749
$0.0341(0.0266)$

Yes

Yes

Yes

Yes

$14.1444^{*}(2.8783)$

0.787 (within) 728

$p$ value, ${ }^{*} p<0.1 ;{ }^{* *} p<0.5 ;{ }^{* * *} p<0.1$. Robust standard errors in parentheses (clustered by city).

\section{Discussion and Conclusions}

7.1. Discussion. Based on the balanced panel data of 109 prefecture-level cities in China from 2010 to 2016, this paper empirically analyzed the impact of ride-hailing services on the use of private cars in urban areas. The main conclusions were as follows: (1) ride-hailing services had a significant negative impact on the use of private cars in urban areas; (2) in the long run, the negative impact of ride-hailing services on the use of private cars in urban areas initially strengthened and then weakened; (3) ride-hailing services had a greater negative impact on private car use in eastern cities, whereas ride-hailing services had no significant impact on private car use in western cities.

Travel by private cars is convenient and flexible, and it is a very appealing travel mode for citizens [50, 51, 80]. Most of the vehicles joining ride-hailing platforms are private cars, which have the same functions, comfort, and convenience as private cars. Based on rational choice theory, a traveler will comprehensively consider costs, time, comfort, convenience, parking pressure, and so on in the choice to use a ride-hailing service or take a private car. Compared with using private cars, ride-hailing has cost advantages (e.g., no expensive upfront purchase or parking cost) and convenience advantages (e.g., there is no need to find a place to park) and so on. Thus, many travelers are willing to abandon private cars to travel and use ride-hailing services when ride-hailing service enters the city. We find that ride-hailing services have a greater negative impact on the use of private cars in 2015 than in 2014. The principal reason is that Uber and Didi fought a price war, where Uber lost $\$ 1$ billion a year in the price war with Didi Kuaidi in China. For more details, refer to the article at the following link: http://help.3g.163.com/16/0223/08/ BGGEDCUN00964KN4.html (in Chinese). Both services offered very high subsidies for passengers and drivers. When a ride-hailing platform provides high subsidies, the advantages of ride-hailing services relative to private cars are more obvious to travelers, and more travelers are willing to choose ride-hailing services.

However, after high subsidies for ride-hailing platform are reduced, for travelers, the advantages of ride-hailing services relative to private cars will be reduced. According to a certain effect from prospect theory, using private cars to travel is more certain than using a ride-hailing service, and this certainty is attractive to many people. People weigh the tension between cost and the feeling of certainty. When the cost of ride-hailing increases, it is outweighed by the feeling of certainty (use private cars to travel). In addition, driving will become a pleasure and habit for private car owners $[47,48,81]$. Therefore, when the advantages of ride-hailing over private cars are no longer obvious, many traveler use private cars to travel. Therefore, the number of people traveling by private cars will increase. Another interesting finding emerged from the regression analyses. Ride-hailing services had a less negative impact on private car use in 2016 than in 2014. There was no high subsidy policy in 2014 or 2016, and the high subsidy policy was only implemented in 2015. It led to a sharp rise in the use of private cars after the policy was suddenly cancelled, and the quantity after the rebound was even larger than that before the policy was implemented. This phenomenon can also be explained by prospect theory. According to the endowment effect from prospect theory, the "loss" brought by the cancellation of some goods is greater than the "gain" brought by the acquisition of the same quantity of the goods. When travelers realize that they have lost the high subsidy, their feeling of loss is much larger than their happiness when they acquired the subsidy. They are more inclined to use private cars to travel after the cancellation of high subsidies. Subsidies will increase the platform's appeal to both drivers and passengers. Guo et al. [75] found that the subsidy policy substantially attracts many people to be ride-hailing drivers and then increases the new car sales. Our finding suggests that subsidy policy has a negative impact on the use of private cars. In comparison, becoming a ride-hailing driver requires considering more factors, taking on more costs, and being more cautious; however, passengers can make decisions quickly and may change their travel behavior. Therefore, platform subsidies attract travelers more easily than they attract drivers, and it is easier for the platforms to reach a critical mass. Therefore, ride-hailing services have a negative impact on the use of private cars in urban areas.

The heterogeneity analysis showed that ride-hailing services had a more significant negative impact on private car use in eastern cities. The economic level of eastern cities is higher and people's expectations for quality of life are relatively high, but the cost of living in an eastern city is also high (e.g., housing prices are generally high), the parking 
pressure is greater, the proportion of the population that is young is high [82], and the pressures of city life are generally greater, which increases the difficulty of using a private car. Travelers will weigh the pros and cons of ride-hailing services and private cars based on rational choice theory when the economic conditions of the travelers are not moderate, demand for private cars is elastic, and cities have travel mode options that function very similarly to private cars. Generally, when ride-hailing services are used infrequently, the total cost of their usage is not high; however, the cost of using a private car remains high because it includes the purchase of the car, maintenance, fuel consumption, and parking. Therefore, in this case, many travelers would not choose to use a private car for travel, and they are more willing to choose ride-hailing services. This finding explains why ridehailing services have a greater negative impact on private car use in eastern cities.

This paper is different from previous studies in several respects. First, Guo et al. [25] and Guo et al. [74] mainly discuss the impact of a ride-hailing service (Didi Chuxing) on new car sales. This paper mainly discusses ride-hailing services (Uber and Didi Chuxing) on the use of private cars in urban areas. We adopted private car ownership as a proxy variable for private car usage because it is difficult to collect data on private car usage in our sample cities, and private car ownership and private car usage in cities are highly and positively correlated. As is widely known, China is a developing country with low per capita income. For most private car owners, the demand for travel via private car is inelastic. People tend not to own private cars if they find that traveling by private car is not necessary. Private cars are a comfortable and convenient mode of travel. Therefore, Chinese families are willing to travel by private car once they own one. As described by Button et al., in low-income countries, although the use of private cars is affected by factors such as income, gas prices, urbanization, and road conditions, once people own a private car, they rely on their private car to travel [41]. Similarly, Wang et al. found private car owners in Beijing strongly depend on their private cars and tend not to travel by other modes. Additionally, they found that once a family owns a private car, the family members use it for commuting no matter how far away they are from their workplaces [42]. Van Acker and Witlox studied the relationship between the built environment and private car use by taking private car ownership as a mediating variable and found that private car use is highly correlated with private car ownership [43]. Some scholars have demonstrated that the dependence of car owners on their private cars is not affected by the alternative means of transportation available. For example, Cao et al. and Shen et al. both found that residents living near a subway station do not significantly reduce their use of private cars [44, 45]. In addition, the survey conducted by Cullinane indicated that although the public transit network in Hong Kong is very developed, once people have a private car, they exhibit a high dependence on their private car for travel [52]. Guo et al. [25] and Guo et al. [74], who focused on new car sales and registrations, used data from the Chinese Vehicle Management Offices under the administration of the
Ministry of Public Security. We focused on private car usage (private car ownership), and our data are from the China City Statistical Yearbook.

Second, we considered two leading ride-hailing platforms (Uber and Didi Chuxing) and found that ride-hailing services had a negative impact on the use of private cars in urban areas. This conclusion differs from Guo et al. [25] and Guo et al. [74], who found that Didi Chuxing had a positive impact on new car sales. On the one hand, our research object is different from Guo et al. [25] and Guo et al. [74], who focused on new car sales, while we focused on private car usage. On the other hand, we considered the case of two leading ride-hailing platforms (Uber and Didi Chuxing), while Guo et al. [25] and Guo et al. [74] only considered one platform. This indicates that the impact of different ridehailing platforms (ride-hailing services) on new car sales or private car use is heterogeneous and needs to be studied in the future.

Third, Guo et al. [74] conducted a dynamic effect analysis of only one year in their study and failed to capture the attractive effect of the ride-hailing platform's promotional subsidy on passengers and drivers, leading to an insufficient analysis of the problem. In studying the impact of ridehailing services on private car use in urban areas, we conducted a two-year dynamic effect analysis, which can capture the attractive effect of promotional subsidies from ride-hailing platforms on passengers and drivers.

Fourth, when conducting a robustness test on the change in new car sales before Didi Chuxing entered the experimental city, the previous study only altered the entrance of Didi Chuxing into the city by a month. When we conducted our robustness test on the impact of ride-hailing services on the use of private cars in urban areas, we altered the entrance of ride-hailing cars entering the experimental city by two to three years, which enhances the persuasiveness of the counterfactual effect in this paper and reduces the likelihood that our results are due to chance.

Fifth, Guo et al. [75] found that the competitive effect of ride-hailing services (Uber and Didi Chuxing) had a positive impact on new car sales and that the ride-hailing platforms mainly provided subsidies for drivers so that a large number of drivers bought new cars in order to join the ride-hailing platform. We find that ride-hailing services have a negative impact on the use of private cars. We believe that platform subsidies for passengers are more likely to push platforms to a critical mass and generate word-of-mouth effects and are more likely to change the travel behavior of passengers. In the promotional process of ride-hailing platforms, subsidies are given to both drivers and passengers in order to reach a critical mass. Subsidies may create tension in the overall volume of private cars used in the city. On the one hand, subsidies to passengers reduce their willingness to use private cars and therefore decrease the usage of private cars in the city. On the other hand, as verified by Guo et al. [25], Guo et al. [74], and Guo et al. [75], subsidies to drivers may spur them towards buying new cars to join the ride-hailing service and may increase the usage of private cars in the city. 
7.2. Theoretical Contribution. This paper was the first study to use official data to test the impact of ride-hailing services on the use of private cars in China's cities. It enriches the research on the effect of ride-hailing services in cities.

We developed the theoretical analysis on the effect of ride-hailing services based on a combination of rational choice theory and prospect theory. Then, we verified for the first time that ride-hailing services had a significant, negative impact on the use of private cars in Chinese cities. Then, we also found how the negative impact changed over time and revealed the heterogeneity of its negative influence in different urban locations. These findings lay a solid foundation for research on the influence of ride-hailing services on tradition travel modes in cities.

7.3. Implications for Policy. The research conclusions of this paper have some practical implications. We demonstrate that ride-hailing services have a negative impact on the use of private cars in urban areas, which can provide a reference for the government to formulate polices for ride-hailing. As a new transportation industry, ridehailing brings extra options to transport in cities, facilitates citizens' daily travel, improves the utilization of automobiles, alleviates the high cost of private car parking and the shortage of parking spaces to a certain extent, and contributes to urban transportation and the environment. Based on these effects, the government, especially in eastern cities, needs to govern the ride-hailing platform rationally and optimize the ride-hailing services size so that it cannot only facilitate citizens' daily travel but also produce a "substitution effect" on the use of private cars in urban areas.

Our conclusion also provides important information for car dealers. We find the entry of ride-hailing services to negatively impact the use of private cars, and we also find this impact is different in different cities. Therefore, car dealers should adjust their marketing strategies. In large eastern cities especially, they need seek cooperation with ride-hailing services platforms. For example, a car dealer may give discount prices to ride-hailing cars. This effort may increase the dealer's sales.

7.4. Limitations and Future Research. There are also some limitations in this study, which are expected to be overcome in future studies.

(1) This paper uses annual data to analyze the impact of ride-hailing services on the use of private cars in urban areas, which makes the time dimension of the dynamic effect relatively short. If monthly data on ride-hailing services in cities can be obtained in future research, this problem could be addressed.

(2) Further research should also extend to the impact of ride-hailing services on other modes of transportation and the impact of ride-hailing services on urban traffic congestion.

\section{Data Availability}

The data used to support the findings of this study are available from the corresponding author upon request.

\section{Conflicts of Interest}

The authors declare no conflicts of interest.

\section{Authors' Contributions}

Jun Zhong was responsible for conceptualization, methodology, and writing the original draft. Lin Yan was responsible of project administration, and Siqi Yang was responsible of data curation. All authors have read and agreed on the published version of the manuscript.

\section{Acknowledgments}

The authors would like to thank National Bureau of Statistics for the open data. This work was supported by National Natural Science Foundation of China (no. 71571025) and the Fundamental Research Funds for the Central Universities (no. 3132019353).

\section{References}

[1] C. Yan, H. Zhu, and N. Korolko, "Dynamic pricing and matching in ride-hailing platform," Naval Research Logistics (NRL), 2012.

[2] M. Vanderschuren and J. Baufeldt, "Ride-sharing: a potential means to increase the quality and availability of motorised trips while discouraging private motor ownership in developing cities?" Research in Transportation Economics, vol. 69, pp. 607-614, 2018.

[3] D. J. Fagnant and K. M. Kockelman, "The travel and environmental implications of shared autonomous vehicles, using agent-based model scenarios," Transportation Research Part C: Emerging Technologies, vol. 40, pp. 1-13, 2014.

[4] H. Cai, X. Wang, P. Adriaens, and M. Xu, "Environmental benefits of taxi ride sharing in Beijing," Energy, vol. 174, pp. 503-508, 2019.

[5] A. Acheampong, A. Siiba, K. Okyere et al., "Mobility-ondemand: an empirical study of internet-based ride-hailing adoption factors, travel characteristics and mode substitution effects," Transportation Research Part C Emerging Technologies, vol. 115, Article ID 102638, 2020.

[6] B. Tang, L. Xiao-Yi, Y. Biying et al., "How app-based ridehailing services influence travel behavior: an empirical study from China," International Journal of Sustainable Transportation, vol. 14, no. 7, pp. 554-568, 2020.

[7] A. E. Brown, "Who and where rideshares? Rideshare travel and use in Los Angeles," Transportation Research Part A: Policy and Practice, vol. 136, pp. 120-134, 2020.

[8] N. Malalgoda and S. H. Lim, "Do transportation network companies reduce public transit use in the U.S.?" Transportation Research Part A: Policy and Practice, vol. 130, pp. 351-372, 2019.

[9] K. Kim, C. Baek, and J.-D. Lee, "Creative destruction of the sharing economy in action: the case of Uber," Transportation Research Part A: Policy and Practice, vol. 110, pp. 118-127, 2018. 
[10] J. W. Ward, J. J. Michalek, and I. L. Azevedo, "On-demand ride-sourcing has reduced per-capita vehicle registrations and gasoline use in US states," in Proceedings of the 97th Annual Meeting of the Transportation Research Board, Washington, DC, USA, 2018.

[11] Q. Xing, Z. Chen, Z. Zhang et al., "Charging demand forecasting model for electric vehicles based on online ride-hailing trip data," IEEE Access, vol. 7, pp. 137390-137409, 2019.

[12] J. W. Ward, J. J. Michalek, I. L. Azevedo, C. Samaras, and P. Ferreira, "Effects of on-demand ride sourcing on vehicle ownership, fuel consumption, vehicle miles traveled, and emissions per capita in US. States," Transportation Research Part C: Emerging Technologies, vol. 108, pp. 289-301, 2019.

[13] J. Gong, B. N. Greenwood, and Y. Song, "Uber might buy me a mercedes benz: an empirical investigation of the sharing economy and durable goods purchase," 2017, https://ssrn. com/abstract $=2971072$.

[14] L. Einav, C. Farronato, and J. Levin, "Peer-to-peer markets," Annual Review of Economics, vol. 8, no. 1, pp. 615-635, 2016.

[15] J. P. Bailey and Y. Bakos, "An exploratory study of the emerging role of electronic intermediaries," International Journal of Electronic Commerce, vol. 1, no. 3, pp. 7-20, 1997.

[16] E. Brynjolfsson, Y. Hu, and M. D. Smith, "Consumer surplus in the digital economy: estimating the value of increased product variety at online booksellers," Management Science, vol. 49, no. 11, pp. 1580-1596, 2003.

[17] O. E. Williamson, "The economics of organization: the transaction cost approach," American Journal of Sociology, vol. 87, no. 3, pp. 548-577, 1981.

[18] G. Zervas, D. Proserpio, and J. W. Byers, "The rise of the sharing economy: estimating the impact of Airbnb on the hotel industry," Journal of Marketing Research, vol. 54, no. 5, pp. 687-705, 2017.

[19] T. Dogru, M. Mody, and C. Suess, "Adding evidence to the debate: quantifying Airbnb's disruptive impact on ten key hotel markets," Tourism Management, vol. 72, pp. 27-38, 2019.

[20] J. Haywood, P. Mayock, J. Freitag, K. A. Owoo, and B. Fiorilla, "Airbnb\&hotel performance: an analysis of proprietary data in 13 global markets," 2017, http://www.hotelnewsnow.com/ Articles/106670/STR-research-Airbnb-hotel-data-in-13global-markets.

[21] R. R. Clewlow and G. S. Mishra., "Disruptive transportation: the adoption, utilization, and impacts of ride-hailing in the united states," 2017, https://skift.com/wp-content/uploads/ 2017/10/2017_UCD-ITS-RR-17-07.pdf.

[22] J. D. Hall, C. Palsson, and J. Price, "Is Uber a substitute or complement for public transit?" Journal of Urban Economics, vol. 108, pp. 36-50, 2018.

[23] T. Berger, C. Chen, and C. B. Frey, "Drivers of disruption? estimating the uber effect," European Economic Review, vol. 110, pp. 197-210, 2018.

[24] S. Wallsten, "The competitive impacts of the sharing economy: how is uber changing taxis," 2015, https://www. researchgate.net/publication/279514652.

[25] Y. Guo, F. Xin, S. J. Barnes, and X. Li, "Opportunities or threats: the rise of online collaborative consumption (OCC) and its impact on new car sales," Electronic Commerce Research and Applications, vol. 29, pp. 133-141, 2018.

[26] H. Gan and Y. Bai, "The effect of travel time variability on route choice decision: a generalized linear mixed model based analysis," Transportation, vol. 41, no. 2, pp. 339-350, 2014.

[27] Y. Zhang, H. Guo, C. Li, W. Wang, X. Jiang, and Y. Liu, "Which one is more attractive to traveler, taxi or tailored taxi?
An empirical study in China," Procedia Engineering, vol. 137, pp. 867-875, 2016.

[28] S. Ghader, A. Darzi, and L. Zhang, "Modeling effects of travel time reliability on mode choice using cumulative prospect theory," Transportation Research Part C: Emerging Technologies, vol. 108, pp. 245-254, 2019.

[29] J. Conlisk, "Why bounded rationality?" Journal of Economic Literature, vol. 34, no. 2, pp. 669-700, 1996.

[30] P. Boelhouwer, "Neo-classical economic theory on housing markets and behavioural sciences: Ally or opponent?" Housing, Theory and Society, vol. 28, no. 3, pp. 276-280, 2011.

[31] M. Mahmoudi and M. Pingle, "Bounded rationality, ambiguity, and choice," Journal of Behavioral and Experimental Economics, vol. 75, pp. 141-153, 2018.

[32] H. Li, J. Zhang, and R. Sarathy, "Understanding compliance with internet use policy from the perspective of rational choice theory," Decision Support Systems, vol. 48, no. 4, pp. 635-645, 2010.

[33] I. Piliavin, R. Gartner, C. Thornton, and R. L. Matsueda, "Crime, deterrence, and rational choice," American Sociological Review, vol. 51, no. 1, pp. 101-119, 1986.

[34] D. Alonso and P. Fernández-Berrocal, "Irrational decisions: attending to numbers rather than ratios," Personality and Individual Differences, vol. 35, no. 7, pp. 1537-1547, 2003.

[35] J. D. Clough, "Using prospect theory to understand end-oflife decisions," Journal of Clinical Oncology, vol. 25, no. 29, 4700 pages, 2007.

[36] A. Tversky and D. Kahneman, "Prospect theory: an analysis of decision under risk," Econometrica, vol. 47, no. 2, pp. 263-291, 1979.

[37] T. C. Sebora and J. R. Cornwall, "Expected utility theory vs. prospect theory: implications for strategic decision-makers," Journal of Managerial Issues, vol. 7, no. 1, pp. 41-61, 1995.

[38] K. D. Edwards, "Prospect theory: a literature review," International Review of Financial Analysis, vol. 5, no. 1, pp. 19-38, 1996.

[39] P. C. Mayer, "Electricity conservation: consumer rationality versus prospect theory," Contemporary Economic Policy, vol. 13, no. 2, pp. 109-118, 1995.

[40] A. Liu, T. Wuest, W. Wei, and S. Lu, "Application of prospect theory on car sharing product service system," Procedia CIRP, vol. 16, pp. 350-355, 2014.

[41] K. Button, N. Ngoe, and J. L. Hine, "Modeling vehicle ownership and use in low income countries," Journal of Transport Economics and Policy, vol. 27, no. 1, pp. 51-67, 1993.

[42] F. Wang and D. Wang, "Characteristics and determinants of car use in Beijing," Acta Geography, vol. 69, pp. 771-781, 2014.

[43] V. Acker and F. Witlox, "Car ownership as a mediating variable in car travel behaviour research using a structural equation modelling approach to identify its dual relationship," Journal of Transport Geography, vol. 18, no. 1, pp. 6574, 2010.

[44] J. Cao and X. Cao, "The impacts of LRT, neighbourhood characteristics, and self-selection on auto ownership: evidence from minneapolis-st. Paul," Urban Studies, vol. 51, no. 10, pp. 2068-2087, 2014.

[45] Q. Shen, P. Chen, and H. Pan, "Factors affecting car ownership and mode choice in rail transit-supported suburbs of a large Chinese city," Transportation Research Part A: Policy and Practice, vol. 94, pp. 31-44, 2016.

[46] A. Bazrbachi, S. F. Sidique, M. N. Shamsudin, A. Radam, S. Kaffashi, and S. U. Adam, "Willingness to pay to improve air quality: a study of private vehicle owners in Klang valley, 
Malaysia," Journal of Cleaner Production, vol. 148, pp. 73-83, 2017.

[47] J. Thøgersen, "Understanding repetitive travel mode choices in a stable context: a panel study approach," Transportation Research Part A Policy and Practice, vol. 40, no. 8, pp. 621-638, 2006.

[48] T. Gärling, S. Fujii, and O. Boe, "Empirical tests of a model of determinants of script-based driving choice," Transportation Research Part F: Traffic Psychology and Behaviour, vol. 4, no. 2, pp. 89-102, 2001.

[49] B. Lanken, H. Aarts, V Knippenberg et al., "Attitude versus general habit: antecedents of travel mode choice," Journal of Applied Social Psychology, vol. 24, no. 4, pp. 285-300, 1994.

[50] S. Tao, S. Y. He, and J. Thøgersen, "The role of car ownership in attitudes towards public transport: a comparative study of Guangzhou and Brisbane," Transportation Research Part F: Traffic Psychology and Behaviour, vol. 60, pp. 685-699, 2019.

[51] G. Beirão and J. A. Sarsfield Cabral, "Understanding attitudes towards public transport and private car: a qualitative study," Transport Policy, vol. 14, no. 6, pp. 478-489, 2007.

[52] K. Cullinane and S. Cullinane, "Car dependence in a public transport dominated city: evidence from Hong Kong," Transportation Research Part D Transport and Environment, vol. 8, no. 2, pp. 129-138, 2003.

[53] T. B. Bjørner, Persontransport med bil (person transport by car), AKF Forlaget, København, Denmark, 1994.

[54] G. Bresson, J. Dargay, J.-L. Madre, and A. Pirotte, "Economic and structural determinants of the demand for public transport: an analysis on a panel of French urban areas using shrinkage estimators," Transportation Research Part A Policy and Practice, vol. 38, no. 4, pp. 269-285, 2004.

[55] W. N. Zhao and Q. Zhang, "A study on the determinants of private car ownership in China: findings from the panel data," Transportation Research Part A: Policy and Practice, vol. 85, pp. 186-195, 2016.

[56] C. Jakobsson, S. Fujii, and T. Gärling, "Determinants of private car users' acceptance of road pricing," Transport Policy, vol. 7, no. 2, pp. 153-158, 2000.

[57] J. Firnkorn and M. Müller, "Free-floating electric carsharingfleets in smart cities: the dawning of a post-private car era in urban environments?" Environmental Science \& Policy, vol. 45, pp. 30-40, 2015.

[58] S. H. Tørnblad, S. Kallbekken, and K. Korneliussen, "Using mobility management to reduce private car use: results from a natural field experiment in Norway," Transport Policy, vol. 32, pp. 9-15, 2014.

[59] D. A. del Sol and A. Gragera, "The impact of curbside parking regulations on car ownership," Documents de Treball (IREA), vol. 81, no. 9, pp. 1-30, 2019.

[60] Y.-J. Zhang, Z. Liu, C.-X. Qin, and T.-D. Tan, “The direct and indirect $\mathrm{CO} 2$ rebound effect for private cars in China," Energy Policy, vol. 100, pp. 149-161, 2017.

[61] A. Bastian and M. Börjesson, "Peak car? drivers of the recent decline in Swedish car use," Transport Policy, vol. 42, pp. 94-102, 2015.

[62] D. Albalate and P. Bel-Piñana, "The effects of public private partnerships on road safety outcomes," Accident Analysis \& Prevention, vol. 128, pp. 53-64, 2019.

[63] O. Travesset-Baro, B. P. Ó. Gallachóir, E. Jover, and M. RosasCasals, "Transport energy demand in Andorra. Assessing private car futures through sensitivity and scenario analysis," Energy Policy, vol. 96, pp. 78-92, 2016.

[64] A. Andersson, "Is climate morality the answer? preconditions affecting the motivation to decrease private car use,"
Transportation Research Part D: Transport and Environment, vol. 78, Article ID 102198, 2020.

[65] H. Becker, F. Ciari, and K. W. Axhausen, "Measuring the car ownership impact of free-floating car-sharing - a case study in Basel, Switzerland," Transportation Research Part D: Transport and Environment, vol. 65, pp. 51-62, 2018.

[66] S. Li and P. Zhao, "Exploring car ownership and car use in neighborhoods near metro stations in Beijing: does the neighborhood built environment matter?" Transportation Research Part D: Transport and Environment, vol. 56, pp. 1-17, 2017.

[67] L. Wang, L. Li, and B. Wu, "Private car switched to public transit by commuters," Procedia-Social and Behavioral Sciences, vol. 96, pp. 1293-1303, 2013.

[68] P. Zhao and Y. Bai, "The gap between and determinants of growth in car ownership in urban and rural areas of China: a longitudinal data case study," Journal of Transport Geography, vol. 79, Article ID 102487, 2019.

[69] M. M. Hamed and H. H. Olaywah, "Travel-related decisions by bus, servis taxi, and private car commuters in the city of Amman, Jordan," Cities, vol. 17, no. 1, pp. 63-71, 2000.

[70] B. L. Dey, M. M. Babu, M. Rahman, M. Dora, and N. Mishra, "Technology upgrading through co-creation of value in developing societies: analysis of the mobile telephone industry in Bangladesh," Technological Forecasting and Social Change, vol. 145, pp. 413-425, 2019.

[71] H. Pan, Q. Shen, and M. Zhang, "Influence of urban form on travel behaviour in four neighbourhoods of Shanghai," Urban Studies, vol. 46, no. 2, pp. 275-294, 2009.

[72] Y. Zhang, W. Wu, Y. Li, Q. Liu, and C. Li, "Does the built environment make a difference? An investigation of household vehicle use in Zhongshan metropolitan area, China," Sustainability, vol. 6, no. 8, pp. 4910-4930, 2014.

[73] T. Thao and T. Ohnmacht, "Ihe impact of the built environment on travel behavior: the swiss experience based on two national travel surveys," Research in Transportation Business \& Management, Article ID 100386, 2019.

[74] Y. Guo, F. Xin, and X. T. Li, "The market impacts of sharing economy entrants: evidence from usa and china," Electronic Commerce Research, vol. 20, pp. 629-649, 2020.

[75] Y. Guo, X. Li, and X. Zeng, "Platform competition in the sharing economy: understanding how ride-hailing services influence new car purchases," Journal of Management Information Systems, vol. 36, no. 4, pp. 1043-1070, 2019.

[76] B. Walsh, A. Nolan, A. Brick, and C. Keegan, "Did the expansion of free GP care impact demand for Emergency Department attendances? A difference-in-differences analysis," Social Science \& Medicine, vol. 222, pp. 101-111, 2019.

[77] H. Li, D. J. Graham, and A. Majumdar, "The effects of congestion charging on road traffic casualties: a causal analysis using difference-in-difference estimation," Accident Analysis \& Prevention, vol. 49, pp. 366-377, 2012.

[78] H. Wang, Z. Chen, X. Wu, and X. Nie, "Can a carbon trading system promote the transformation of a low-carbon economy under the framework of the porter hypothesis? empirical analysis based on the PSM-DID method," Energy Policy, vol. 129, pp. 930-938, 2019.

[79] J. Zang, L. Wan, and Z. Li, "Does emission trading scheme have spillover effect on industrial structure upgrading? Evidence from the EU based on a PSM-DID approach," Environmental Science and Pollution Research, vol. 28, pp. 1-13, 2020. 
[80] A. Simma and W. Axhausen, "Structures of commitment in mode use: a comparison of Switzerland," Germany and Great Britain. Transport Policy, vol. 8, no. 4, pp. 279-288, 2001.

[81] B. Verplanken, A. H. Aarts, and A. Moonen, "Habit versus planned behaviour: a field experiment," British Journal of Social Psychology, vol. 37, no. 1, pp. 111-128, 1998.

[82] Q. Q. Tencent, "National urban youth index report," 2016, http://www.199it.com/archives/469119.html. 